\title{
ESG DISCLOSURE PATTERNS IN THE BALTICS
}

\author{
Ilze Zumente ${ }^{1}$, Nataljja Lāce ${ }^{2}$, Jūlija Bistrova ${ }^{3}$ \\ Riga Technical University, Riga, Latvia \\ E-mails: ${ }^{1}$ ilze.zumente@gmail.com; '2natalja.lace@rtu.lv (corresponding author); \\ 3julija.bistrova@rtu.lv \\ Received 18 February 2020; accepted 06 May 2020
}

\begin{abstract}
The goal of this article is to provide evidence on the volume of ESG disclosures of 34 companies listed on the NASDAQ Baltic stock exchange. It provides a broad view of the non-financial disclosure thoroughness and offers conclusions on the key characteristics of the Baltic listed companies in terms of ESG. By performing content analysis of the publicly available reports based on 106 ESG criteria and statistical analysis of the retrieved data, the disclosure patterns across reporting dimensions, industries, and company characteristics are analyzed. Authors find a wide range (8\% to 67\%) ESG transparency scores with an average of $41 \%$. On aggregate, governance and social dimensions are reported better $(49 \%$ and $44 \%)$ than environmental (24\%). Correlation analysis was performed to test the correlation between ESG and selected financial metrics revealing that the ESG disclosure score correlates with the firm's market capitalization.
\end{abstract}

Keywords: ESG, ESG disclosure, sustainability reporting, non-financial disclosure, corporate social responsibility.

JEL Classification: G30, G32, Q56, M14.

\section{Introduction}

The environmental, social and governance (ESG) factors as a tool for choosing sustainable investments have been increasingly trending in the markets for the last decade. The academic literature tends to largely support the positive ESG and corporate financial performance relationship. A recent meta-study by Friede et al. (2015) has summarized that around $90 \%$ of the academic papers in their sample reveal improved financial performance for companies with better sustainability practices. Consequently, more companies choose in favor of ESG disclosure. According to KPMG data, in 2011, 44\% of the largest global companies included ESG disclosures as part of their annual reporting standards, while in 2017 this number had grown to $78 \%$ (KPMG, 2017).

A part of the ESG trend is dictated by legislative requirements. For the EU countries, the Directive 2014/95/EU on non-financial reporting requires all public interest entities with more than 500 employees to publish reports concerning their actions in environmental protection, social and human rights domain, anti-corruption practices as well as board diversity components. The form of the reporting is relatively liberal leading to the use of differing international (e.g. UN Global Compact and Global Reporting Initiative) and national reporting standards ("Non-financial reporting", 2014).
The disclosure of the ESG information, however, is still far from being unified. Lack of common reporting standards, subjectivity in the assessment and difficulties in measurability are the main challenges why the direct use and relevancy of the ESG report for the investors is complicated and hardly allow for comparisons across the companies (Bassen \& Kovács, 2008). ESG scoring agencies try to eliminate this gap by providing a comparable rating score, however, the scope of the covered and rated companies is still limited. The majority of the companies in the Central and Eastern European (CEE) area including the listed companies of the Baltic countries are currently still not rated by the ESG agencies creating a gap in the understanding of the CEE company compliance with sustainability trend. Besides, lack of information on the ESG disclosure level and performance hinders the inclusion of the Baltic companies in the samples of the academic research.

This article aims at reducing this gap and examines the reporting of the companies listed on the NASDAQ Baltic stock exchange. The previous research on the ESG in the Baltic countries is rather scarce and so far, has concentrated on separate countries rather than the entire listed company pool. The existing evidence includes Gurvitsh and Sidorova (2012), surveying 15 Estonian stock listed companies from 2007 to 2010, as well as 
Rudžionienė et al. (2016), who has performed a literature overview on $\mathrm{E} \& \mathrm{~S}$ disclosure for Lithuania.

To provide the first Baltic wide evidence on the level of ESG disclosure, this article deploys content analysis to evaluate the volume of extra-financial information disclosures in 2018. The research questions are set as follows: (1) What is the level of ESG disclosure among the public companies in the Baltic countries? (2) What factors influence the ESG disclosure level of the listed Baltic companies?

The method of analysis applied involves a detailed evaluation of the reported information against a checklist provided by the NASDAQ Baltic stock exchange as well as an additional list of disclosures compiled as a result of the evaluation. The approach, therefore, yields a more qualitative understanding of the disclosure level and avoids overstating the importance of vaguely compiled, long statements revealing no factual data.

The main contribution of the research is the determination of the volume of the ESG disclosure across the listed Baltic companies, which provides an insight into the current disclosure level across industries, company metrics, and reporting pillars. The results shed light on the improvement areas, which, if undertaken by the stock exchange and policymakers as well as better explained to the companies, could improve the level of the nonfinancial information available to the stakeholders and investors. Besides, the article provides a qualitative baseline for further research on the topic in the Baltic countries.

\section{Literature review}

\subsection{Why do companies disclose?}

The aim of the socially responsible investing (SRI) can be viewed as twofold - firstly, to encourage companies to consider their impact on the society, and secondly, to allow the investors to invest in companies that correspond to their ethical values (York, 2009). SRI and its potential to create higher risk-adjusted returns basing its foundations on the instrumental stakeholder theory have been one of the key questions of investors and asset managers in the last decade. In addition to academic research, this subject is often studied also by asset managers, who use this evidence to make informed decisions on behalf of their clients about investments in one or alternative asset classes. According to research, the primary reason why investors today use ESG data is due to their relevance to investment performance. Other reasons such as specific client requests and ethical considerations come second signaling that financial considerations still dominate the demand for ESG information over ethical reasons (Amel-Zadeh \& Serafeim, 2017).

Concerning the corporate social performance's impact on financial performance, the academics have reached a marginal consensus. Several metastudies as Friede et al. (2015) and Clark et al. (2015) find that around $90 \%$ of the academic papers or more than 2000 studies show a non-negative relationship between the financial performance and ESG proving the positive business case for ESG investing. Other individual studies include Eccles et al. (2014) and Velte (2017), who find evidence suggesting positive ESG impact on the company's profitability measures. Also, Giese et al. (2019), as well as Henisz and McGlinch (2019), find reduced risk metrics attributed to the better scoring ESG companies.

Based on the amounting evidence and the largely unified results documenting the ESG and financial performance relationship, recently the focus of the research has been put on the quantification of the ESG factors and actual consideration of how ESG impact company's market performance, as well as valuation factors.

The efficient market theory states that in efficient capital markets share price shall include all the available information on the security. In the theory, this should serve as one of the general reasons why companies choose to disclose extrafinancial information aiming at providing a wider spectrum of available data for analysis leading to a higher valuation. Brooks and Oikonomou (2018) have summarized the main disclosure reasons discussed in the literature, which include, firm's efforts for legitimacy and decreased regulatory burden, improved reputation, enhanced brand value, motivated employees as well as hope for enhanced financial valuation.

The extent of the non-financial disclosure across companies, however, is still far from homogenous. According to Tamimi and Sebastianelli (2017), who examine the ESG disclosures of S\&P 500 companies, the level of the disclosed information varies greatly across the companies. Governance issues are disclosed the most, while environmental topics are rather underreported. Authors also find that larger companies, as well as companies with larger boards of directors, have greater disclosure scores.

The evidence on the financial implications from the disclosures, contrary to the theory, is relatively ambiguous. Fatemi et al. (2018) argue that it is important to understand the motives for non- 
financial disclosure. They explain that according to the voluntary disclosure theory it is predicted that companies with a better ESG performance would also be keen on disclosing, while those who perform worse, will likely avoid reporting. By using data on public U.S. companies for years 2006 to 2011 authors find that strong ESG performance increases the firm's value, while ESG's weaknesses indeed provide a negative valuation impact. Besides, authors find that there are differences in how investors perceive potential concerns of the separate ESG metrics, namely, stronger valuation discounts are given to the governance concerns, rather than social or environmental issues.

The disclosure type also matters to the valuation. Mervelskemper and Streit (2017) find that ESG performance is valued stronger if a separate ESG report (either stand-alone or an integrated report) is published by a company. Furthermore, the disclosure according to the International Integrated Reporting Council guidelines is found to yield the most positive effect on the valuation by the investors.

Finally, it seems logical that companies operating in different industries are exposed to varying ESG risks. So, for example, a manufacturing company in China will have a higher exposure to environmental and human rights risks than a financial services company operating in the Baltic States. Eccles and Serafeim (2013) describe the trade-off between sustainability endeavors and the financial performance of the companies and conclude that strategical focus on the material ESG issues is necessary to remain on the so-called efficient "performance frontier" and avoid value discretion.

\subsection{Regional ESG evidence}

Most studies that examine ESG and SRI trends concern either U.S. listed companies or look at the global markets. Studies with a focus on Europe or particular European countries are still relatively few. According to von Wallis and Klein (2015), who made an overview of 53 regional SRI studies, the majority or 34 of them were studies examining American companies. Nevertheless, according to van Duuren et al. (2016), European investors value SRI higher than their U.S. based peers. Also, European investors are found to be more optimistic about the potential benefits of ESG based investment screening strategies.

Evidence about CEE countries is quite fragmented and varies across different CEE countries. After the preliminary research of the existing literature Horváth et al. (2017), who performed a CEE wide study, concluded that only a few individual country-level studies exist. The authors, therefore, attempted to fill the gap in the literature and undertook a wider scale study by examining sustainability disclosure patterns across 50 largest companies in ten CEE countries. The annual reports and disclosures of both public and private companies with the largest revenue per country were analyzed by native speakers of the local languages. The conclusions revealed that Polish and Romanian companies lead in terms of the highest proportion of stand-alone reports, while only a few Latvian and Slovenian companies issue a stand-alone sustainability report (instead, they prefer to disclose sustainability information using different media e.g. website). The authors failed to come up with CEE wide patterns for cultural, economic or historical reasons as potential explanatory factors for the disclosure patterns (Horváth et al., 2017).

Other CEE studies include Kocmanova et al. (2011), who performed an overview of ESG factor importance in small and medium enterprises (SMEs) in the Czech Republic, finding that the majority of the surveyed SMEs choose to disclose ESG related information within sections of the annual report. The key concentration topics include waste minimization for an environmental pillar and occupational health and safety monitoring for the social pillar. Kocmanova et al. (2016) further tested the Czech manufacturing company sample by comparing the predictive models with and without sustainability factor inclusion concluding that nonfinancial factor inclusion strongly benefits the prediction power and informative ability of the estimation equation. Czerwińska and Kaźmierkiewicz (2015) investigated the Polish publicly traded companies and found that higher ESG disclosure level is associated with lower volatility and higher returns. The overall level of the nonfinancial reporting on the Polish stock exchange, however, was concluded to be low.

Literature about Baltic countries is rather limited. The most extensive evidence comes from Rudžionienè et al. (2016), who have performed a literature review of 14 research papers about social and environmental information (SEI) disclosure of Lithuanian companies published between 2000 and 2015. The general conclusion is that the amount of SEI disclosure has increased over time. In addition, the findings of the studies exploring the relationship between SEI disclosure and company profiles, reveal several individual conclusions - (1) financial services companies disclose more social information, (2) service companies report the least 
amount of SEI information, (3) manufacturing companies provide higher quality environmental than social information. The determinants as the size and industry of the company are found having an impact on the disclosure volume, however, this conclusion is not unanimous and varies across studies. Finally, the authors suggest that as due to the historic legacy Lithuanian companies might have a bias towards presenting a "better reality" in reports, an integrity perspective examination of the disclosed information could be performed as part of the future research.

Other Lithuanian evidence, coming from a small sample study done by Dagilienè (2013), found no evidence of corporate responsibility reporting influence on a company's market value. In a different paper, the same author and colleagues described the general problematic of consistent sustainability reporting standards in Lithuania caused by the lack of unified reporting standards and guidelines imposed by the legal frameworks (Dagiliene et al., 2014).

Estonian evidence follows from Gurvitsh and Sidorova (2012), who surveyed 15 Estonian stock listed companies and examined their social and environmental accounting disclosures in their annual reports or publications on their webpage. The data for 2007 to 2010 indicated an uptrend in the reporting practices as well as confirmed the previously stated hypothesis that the reporting patterns across the sample companies are highly diverse and hardly comparable.

Previous studies done in Latvia mostly concentrate on corporate governance aspects of sustainability reporting, however, do not include broader reporting patterns about environmental and social domain disclosures of Latvia based companies.

\section{Data}

As of January 2020, there were 34 companies listed on the prime list of the NASDAQ Baltics stock exchange -13 of them headquartered in Lithuania, 17 in Estonia and 4 in Latvia. The industry split of the companies surveyed is presented in Table 1.

Companies are required to publish their financial and non-financial disclosures on the webpage of the stock exchange. The non-financial disclosures constituted the raw data used for the analysis. To create a data set of the reported metrics, the reports of the prime-listed companies were screened. As there is no distinct requirement for the form of reporting, the means of publication presented a great variety. The reports screened included dedicated ESG reports, social responsibility and sustainability reports, compliances to the corporate governance codes as well as dedicated sections of the general annual reports (AR). In case an ESG or Social responsibility report was present, it was evaluated together with the AR. Most disclosure documents screened presented data for 2018, except for two ESG reports for the year 2017 belonging to companies disclosing bi-annually.

Table 1. Surveyed companies by industry (source: created by authors)

\begin{tabular}{|l|c|}
\hline \multicolumn{1}{|c|}{ Industry } & Companies \\
\hline Technology & 3 \\
\hline Financials (incl. RE funds) & 6 \\
\hline Consumer goods (excluding food) & 4 \\
\hline Consumer goods (food) & 6 \\
\hline Consumer services & 4 \\
\hline Industrials & 6 \\
\hline Healthcare & 2 \\
\hline Utilities & 3 \\
\hline Total & 34 \\
\hline
\end{tabular}

Reports and information available on the company websites, but not submitted to the stock exchange, were not included in the analysis.

\section{Method}

Content analysis of the reports was performed by using a checklist based on NASDAQ ESG Reporting Guide 2.0 issued in May 2019 (further referred to as "Reporting guide"). The Reporting guide, which is an updated version of the initial guidelines issued in 2017, suggests the key reporting areas for companies wishing to disclose ESG data to their investors and society. While reserving any direct implications or rules for the issuers, the Reporting guide summarizes the key reporting areas by each of the ESG pillars as well as provides examples and suggestions for the variables that can be measured (NASDAQ, 2019). By breaking down the Reporting guide into individual reporting metrics, a total of 53 possible indicators were identified - 18 of them corresponding to the environmental pillar, 17 to the social pillar and 18 to the governance pillar.

The broad topics related to each reporting pillar were summarized as follows:

E - Greenhouse gas emissions and intensity, energy usage, mix and intensity, water usage, environmental policies, climate oversight by 
supervisory board and management, investments into climate risk mitigation;

$\mathrm{S}$ - CEO and gender pay ratio, employee turnover, gender diversity, temporary worker ratio, non-discrimination policy, health, and safety policy including injury rate, human rights, and child and forced labor policy;

G - board diversity and independence, incentivized pay, collective bargaining, supplier code of conduct, ethics and anti-corruption policy, data privacy, ESG reporting, and disclosure practices, external assurance.

Further, basing on Roca and Searcy (2012), the additional indicators chosen by the companies themselves for each of the reporting pillars were identified and sorted according to the corresponding ESG metric. The content analysis revealed a set of additional factors that Baltic companies choose to disclose, the distribution of them across the pillars being 11 for $\mathrm{E}$ dimension, 26 for $\mathrm{S}$ dimension and finally 16 for $\mathrm{G}$ pillar. The high-level general topics additionally revealed include:

E - environmental management system (e.g. ISO 14001), packaging policy, efforts to decrease the usage of paper, recycling policies and recycling ratio, amount of waste generated, use of alternative energy sources, use of electric vehicles;

$\mathrm{S}$ - a set of employee-related metrics (average age, tenure, employee count by levels and genders, training provided), health benefits, internships, description of remuneration policies, social activities including organized events, donations and charities;

$\mathrm{G}$ - list of shareholders, identified stakeholders and their engagement, governance structure, company values (incl. vision and mission), board and supervisory board tenure and biographies, description of risk management practices.

The factors, which partly include indicators suggested in the Global Reporting Initiative (GRI) reporting guidelines, NASDAQ Corporate Governance Code and United Nations Sustainable Development Goals (SDG), were included in the total list if at least three companies were using this key performance indicator (KPI) as disclosure in their non-financial statements. The total amount of the metrics included in the evaluation, therefore, reached 106 and have been summarized in Table 2.

The content analysis of the reports was performed against the created checklist of 106 metrics and one point was awarded for each disclosure that the company was making. It has to be noted that the analysis did not evaluate, how well companies perform on the corresponding metric (e.g. whether the company complies with diversity policy or not), but rather, whether the company is disclosing the information at all. Therefore, the reporting scores that were calculated as a sum of all the individual disclosures, speak of the transparency of the company rather than their ESG performance.

Table 2. Factors used for the evaluation of company disclosures (source: created by authors)

\begin{tabular}{|l|c|c|c|}
\hline & $\begin{array}{c}\text { Reporting } \\
\text { Guide }\end{array}$ & $\begin{array}{c}\text { Additional } \\
\text { KPI's }\end{array}$ & Total \\
\hline $\mathrm{E}$ & 18 & 11 & 29 \\
\hline $\mathrm{S}$ & 17 & 26 & 43 \\
\hline $\mathrm{G}$ & 18 & 16 & 34 \\
\hline Total & 53 & 53 & 106 \\
\hline
\end{tabular}

\section{Results}

As discussed before, there is no set standard of the ESG disclosure for the listed Baltic companies. The analysis, therefore, consequently revealed a wide diversity of the guidelines used for the preparation of the disclosure documents - 18 companies mentioned using NASDAQ Corporate Governance Code, 8 referred to the GRI standards, while 3 companies used European Commission (n.d.) Guidelines, UN SDG and Global Compact reporting principles each. Only two companies admitted to having directly employed the Reporting Guide.

As presented in Table 3 below, with the minimal reporting score of $8 \%$ (8 from 106 metrics reported by a single company) and the maximum point count of 71 , corresponding to $67 \%$, the average score of 43 points or $41 \%$ was achieved by the companies analyzed.

Table 3. Descriptive statistics of the ESG disclosure scores (source: created by authors)

\begin{tabular}{|l|c|c|}
\hline \multicolumn{2}{|c|}{ Information points disclosed } & Percentage \\
\hline Min & 8 & $8 \%$ \\
\hline Max & 71 & $67 \%$ \\
\hline Median & 45.5 & $43 \%$ \\
\hline Average & 43 & $41 \%$ \\
\hline
\end{tabular}

By evaluating the total reported information volume against the theoretical full disclosure, the percentage of the disclosed ESG information was calculated. The results in Figure 1 reveal that the sample companies in total disclose only $24 \%$ of the environmental information while scoring $44 \%$ and $49 \%$ on the social and governance pillars. 


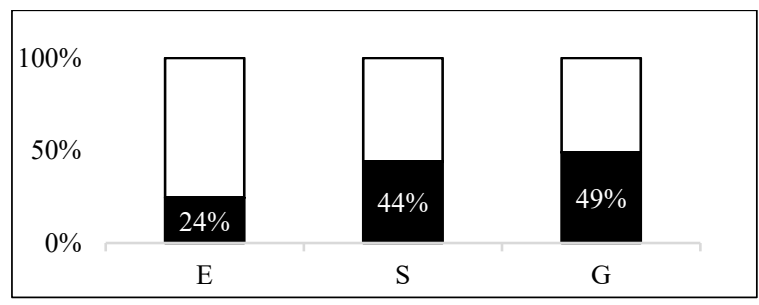

Figure 1. Total disclosed information volume by pillars (\% from full disclosure) (source: created by authors)

When splitting the reported information across the Reporting Guide and Additional KPI's disclosures, the results depicted in Figure 2 improve for the benefit of the Additional KPI's section. This implies that the metrics suggested by the Reporting guide are less popular among the companies examined.

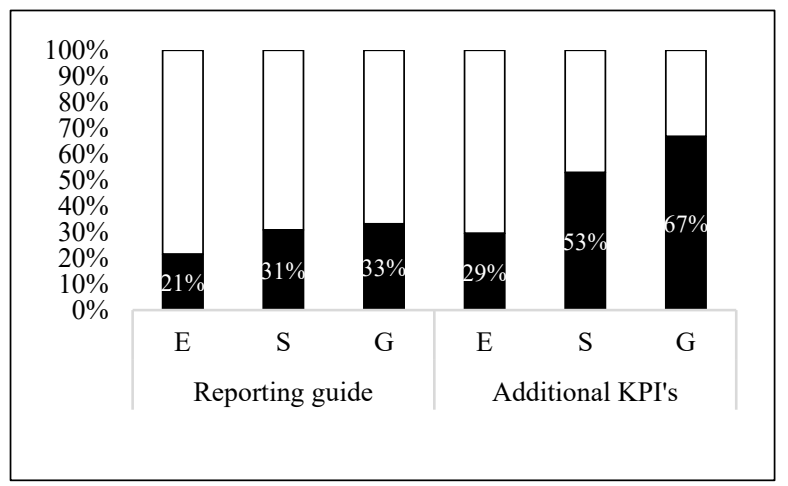

Figure 2. Total disclosed information volume split between Reporting guide and Additional KPI's metrics (source: created by authors)

An additional perspective is provided by the industry analysis presented in Figure 3. By splitting the analyzed companies into clusters according to the industries and taking the average and median scores achieved by each of the clusters, the results show that the highest scores are achieved by companies operating in utilities, healthcare and industrials segments, while companies in technology and financial services (including RE funds) perform worse. The highest scoring industry cluster consisting of utility companies presents the median disclosure score of $63 \%$.

The distribution of the industry split results is more thoroughly explained when analyzing the individual pillar sub-scores of the separate industry clusters (see Figure 4). While social and governance metrics are reported to a fairly similar extent, the largest discrepancy arises from differing environmental disclosure volume, especially in the technology and financial services sector. The highest average volume of social and governance information is reported by companies in the utilities and healthcare segment. Besides, the healthcare companies on average have the most balanced reporting volume across the three ESG pillars.

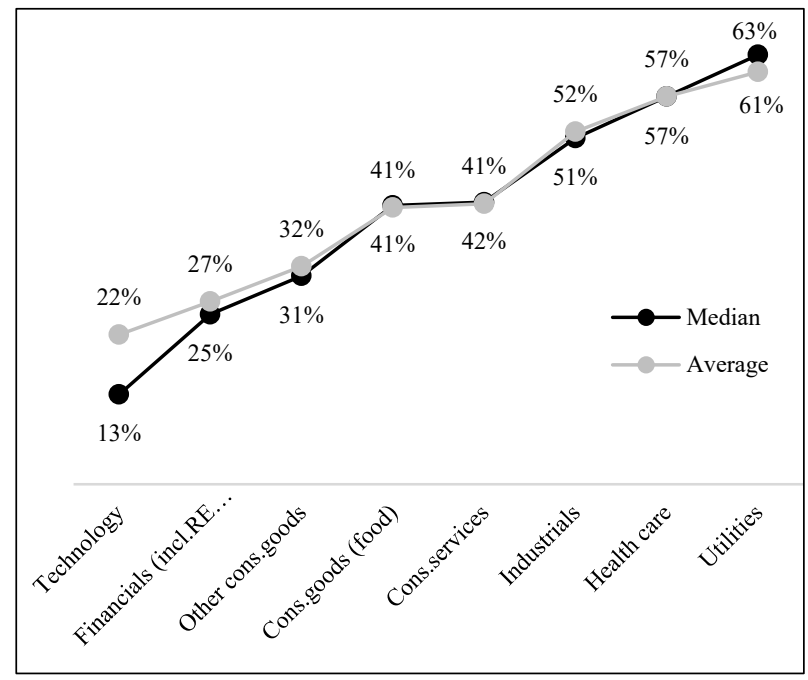

Figure 3. Average and median disclosure volume by industries in percentage (source: created by authors)

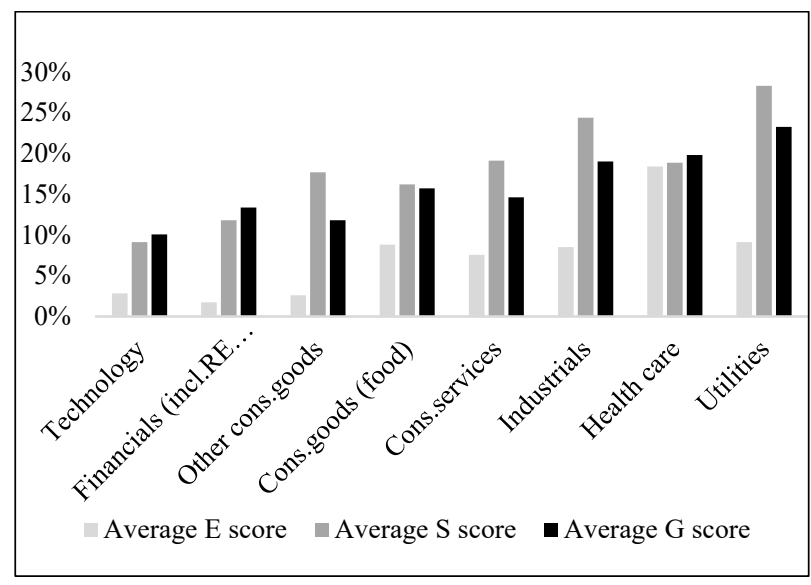

Figure 4. Average disclosure volume split across the pillars and industries (source: created by authors)

Finally, as according to the EU Directive 2014/95/EUR, large public interest entities having more than 500 employees are legally required to perform non-financial disclosures, it would be expected that larger companies should achieve higher overall ESG score. Also, the academic literature suggests that larger companies tend to disclose more. When examining these alleged patterns between the size of the company and its achieved ESG score, the results summarized in Table 4 show a rather inconclusive picture. The revenue of the company as well as employee count both show a rather weak positive correlation with the ESG disclosure score of 0.28 and 0.29 
respectively, thus implying that the size of the company is not the single deciding factor when it comes to the volume of the non-financial information disclosed by the company. Instead, market capitalization seems to have a higher positive correlation with the ESG score of 0.45 reaching even 0.52 for the governance score. Contrary, the company's profitability when measured as the ROE rate, shows a negative correlation to the total ESG score, implying that profitability does not determine the ESG disclosure score for the Baltic listed companies.

Table 4. Correlation matrix (source: created by authors)

\begin{tabular}{|l|c|c|c|c|}
\hline \multicolumn{1}{|c|}{ Correlation } & $\mathrm{E}$ & $\mathrm{S}$ & $\mathrm{G}$ & Total \\
\hline Revenue (2018) & 0.20 & 0.27 & 0.30 & 0.28 \\
\hline $\begin{array}{l}\text { MCAP } \\
\text { (5 Feb 2020) }\end{array}$ & 0.26 & 0.45 & 0.52 & 0.45 \\
\hline $\begin{array}{l}\text { Employees } \\
(2018)\end{array}$ & 0.32 & 0.24 & 0.24 & 0.29 \\
\hline ROE (2018) & $(0.08)$ & $(0.17)$ & $(0.03)$ & $(0.11)$ \\
\hline
\end{tabular}

\section{Discussion}

The scope and practices of the ESG transparency among the Baltic listed companies, as expected, are highly versatile with the range of the disclosure scores varying from $8 \%$ to $67 \%$. While the majority of companies prefer to include their ESG disclosures in the sections of AR (either within the Management report or dedicated sustainability sections), 6 surveyed companies (18\%) have issued a stand-alone sustainability report. The results, when compared to Gurvitsh and Sidorova (2012), who examined 15 Estonian listed companies in years 2007 to 2010, show that even though more companies on average choose to issue stand-alone reports ( $13 \%$ in their sample), the preferred way of reporting in terms of AR section is still unchanged. While only three of the companies with stand-alone reports are in the highest ESG disclosure scoring quartile, it indicates that not always the issuance of a dedicated report directly leads to higher transparency.

The results show that on average companies report a similar volume of social and governancerelated data $(44 \%$ and $49 \%$ of the theoretically possible disclosure volume). While the minimal corporate governance disclosure requirements are set by the stock exchange and are mandatory for all the listed companies, the voluntary social disclosures are almost equally popular. The result thereof largely depends on the high volume of human capital related disclosures that Baltic companies choose to report. The metrics include the splits of employees across various metrics (age, gender, tenure, education) as well as descriptions of the training, motivation systems and extra-financial benefits. In total this section is reported on average by $50 \%$ of all the companies. In addition, over $70 \%$ of companies choose to report on their charitable activities, which similarly increases the total social disclosure volume. The environmental pillar is the least reported among the Baltic companies - in total reaching only $24 \%$ of the theoretically possible disclosure volume. Arguably, the average result is impacted by the relatively high amount of financial and real estate management companies in the sample (6), which due to their nature of operations show only minimal environment-related information. Also, many companies in the manufacturing and utility industries, still choose to include rather vague statements about their environmental consciousness instead of specific, measurable results as mostly suggested by the Reporting guide. So, for example, many companies report on having environmental policies in place, however, they fail to measure and report the actual values of emissions or resource consumption. This result is largely in line with Tamimi and Sebastianelli (2017), who found similar reporting patterns (the highest disclosure for $\mathrm{G}$ factors, while underreporting of $\mathrm{E}$ metrics) for S\&P 500 companies.

When evaluating the materiality argument across the industries, it becomes evident that it partly holds for the Baltic companies. While financial services companies indeed report the lowest volume of the environmental data, on average only a few companies engaged in environmental impact intensive industries do provide wider environmental disclosures. The result is in line with the previous results of the Estonian authors, who discussed that as Estonian companies perceive themselves as sufficiently environmentally friendly, they do not see the direct need to report on specific metrics, instead choosing to report more on social aspects of their business.

While current results suggest that Baltic companies still mostly consider that environmental reporting is only necessary for environmental impact intensive producers, this assumption is increasingly seen as historical by the investors. Instead, companies of all industries shall be prepared to present measurable and quantifiable data of their environmental footprint. As shown by various clever examples in the reports analyzed (e.g. employee flight kilometers, amount of the used paper/water/energy in offices, packaging policies), 
the reporting of environmental efforts is equally possible for non-manufacturing companies.

According to the results, Baltic companies show better results when measured against the set of the Additional KPI disclosure, implying that the metrics suggested by the Reporting guide are less popular among the listed company pool. An explanation might be the higher complexity and specificity of the reporting metrics that are included in the Reporting guide, which would imply that additional explanatory work undertaken by the stock exchange could improve the results. Alternatively, companies may generally feel more inclined to report KPI's that they see as relevant and material for their respective industry and therefore high-level reporting guides cannot provide sufficiently adaptive guidelines. As suggested by Bizoumi et al. (2019) stock exchanges are generally in a unique position to contribute to a wider implementation of ESG practices in company reporting standards and therefore higher overall transparency of the capital markets. Sectoral specificity and emphasis on the material disclosures in the stock exchange issued guidelines shall help to promote the focus on the right sustainability drivers and, by doing so, to increase the ESG disclosure value for the investors.

The results show that the highest median disclosure scores are reached by companies operating in utility (63\%), healthcare $(57 \%)$ and industrials (52\%) segments, while the lowest scores follow from the financial sector (including $\mathrm{RE}$ funds) $(25 \%)$ and technology (13\%) companies. While the results show some similarities with the Lithuanian evidence from Rudžionienè et al. (2016), due to the rather small amount of companies in some segments, the results should be treated with caution as individual company scores can have a disproportionally large contribution to the average and median scores. Nonetheless, it has to be mentioned that several top-scoring companies in the utilities and industrials segments are partly stateowned. Thus, it is possible that the governmental shareholder pressure can be an additional factor relating to higher disclosure scores. If so, it shall be a great example of high transparency ensured by state-owned assets serving as a model also to privately held companies operating in the Baltics.

In line with the assumption that the size of the company impacts the reported ESG information volume, the results of this study indicate that market capitalization of the company strongly correlates (0.45) to the ESG disclosure score. The revenue and number of employees of the company, on the contrary, show a rather limited positive correlation with the total ESG disclosure. This result might suggest that even though larger companies have more resources and shareholder pressure on wider disclosures, many Baltic companies see the ESG disclosure as primary voluntary (or aimed at improving their investor relations) and do not engage in the non-financial reporting only due to the legislative requirements.

\section{Conclusions}

The present study is the first thorough ESGdedicated research on 34 listed companies in three Baltic States investigating the quality of ESG disclosure based on 106 criteria. The primary aim of this study was to determine the volume of the ESG related information disclosed by the companies listed on the NASDAQ Baltic stock exchange prime list. The authors performed content and comparative analyses to evaluate ESG-related information provided within the public reports. The results show a wide range of ESG transparency ranging from 8 points $(8 \%)$ minimum to 71 points $(67 \%)$ maximally achieved by an individual company. The results allow concluding that based on data for 2018, the average ESG disclosure level among the Baltic listed companies is $41 \%$ indicating a moderate level of the aggregate disclosures. In addition, the disclosure level is measured to be $24 \%$ for $\mathrm{E}, 44 \%$ for $\mathrm{S}$ and $49 \%$ for $\mathrm{G}$ across the reporting pillars allowing to conclude that besides the governance-related information, which is more extensively disclosed due to the mandatory stock exchange requirements, most of the companies prefer to disclose performance related to the social aspects, especially stressing employees related data and charitable deeds. Environmental disclosures in the Baltics are less reported, furthermore, in many cases, the reported information is rather vague and lacks specific data suggesting the area for improvement to increase the quality of the nonfinancial reporting. Lesser attention of the Baltic companies to the environmental issues partially are explained by the industry bias: The Baltic main list is better represented by financial and IT sectors, for which environmental issues are less relevant. Additionally, environmental performance is admitted as being harder to measure.

Another valuable contribution to the scientific literature provided by the study is seen in relating ESG disclosure to the financial metrics such as market capitalization, profitability, revenues. It was found that the company's market capitalization presents a reasonably high correlation with the ESG disclosure score allowing to conclude that larger 
companies perform better disclosures, which confirms global evidence on this relationship. However, no correlation was detected between ESG and other selected metrics. In addition, as several of the best scoring companies are partly state-owned, it can be argued that it constitutes another factor impacting the extent of the non-financial disclosure.

Finally, when assessing the reported information volume suggested by the NASDAQ Reporting guide and the disclosure topics chosen by the companies themselves, the latter dominates the overall sample suggesting that companies prefer to disclose information, which is more straight forward to report and easier to compile, indicating the place for improvement for the Baltic companies to reach more sophisticated levels of non-financial reporting.

It should be noted that the research is done solely based on the quality of disclosure and information availability, and the companies were not evaluated based on how well they perform in terms of ESG. This could pave the way for further research when the ESG rating could be developed and the companies can be assessed and compared to their industry peers based on E, S, G metrics. The comparison of the Baltic data with the scores of companies operating in other CEE countries could allow for further comparison and provide conclusions on the Baltic company standing in terms of ESG reporting against an international sample contributing to the gap created by the exclusion of the Baltic companies from the ESG scoring agency radar and, therefore, also from the samples analyzed in the academic research.

\section{Disclosure statement}

The authors do not have any competing financial, professional, or personal interests from other parties.

\section{References}

Amel-Zadeh, A., \& Serafeim, G. (2017). Why and how investors use ESG information: evidence from a global survey (Harvard Business School Working Paper No. 17-079).

https://doi.org/10.2139/ssrn.2925310

Bassen, A., \& Kovács, A. M. (2008). Environmental, social and governance key performance indicators from a capital market perspective. Zeitschrift Für Wirtschafts- Und Unternehmensethik, 9(2), 182-192. https://doi.org/10.5771/1439-880X-2008-2-182

Bizoumi, T., Lazaridis, S., \& Stamou, N. (2019). Innovation in stock exchanges: driving ESG disclosure and performance. Journal of Applied Corporate Finance, 31(2), 72-79.

https://doi.org/10.1111/jacf.12348
Brooks, C., \& Oikonomou, I. (2018). The effects of environmental, social and governance disclosures and performance on firm value: a review of the literature in accounting and finance. The British Accounting Review, 50(1), 1-15. https://doi.org/10.1016/j.bar.2017.11.005

Clark, G., Feiner, A., \& Viehs, M. (2015). From the stockholder to the stakeholder: how sustainability can drive financial outperformance (University of Oxford Working Paper). https://doi.org/10.2139/ssrn.2508281

Czerwińska, T., \& Kaźmierkiewicz, P. (2015). ESG rating in investment risk analysis of companies listed on the public market in Poland. Economic Notes, 44(2), 211-248. https://doi.org/10.1111/ecno.12031

Dagilienè, L. (2013). The influence of corporate social reporting to company's value in a developing economy. Procedia Economics and Finance, 5, 212-221. https://doi.org/10.1016/S2212-5671(13)00027-0

Dagiliene, L., Leitoniene, S., \& Grencikova, A. (2014). Increasing business transparency by corporate social reporting: development and problems in Lithuania. Engineering Economics, 25(1), 54-61. https://doi.org/10.5755/j01.ee.25.1.2356

Eccles, R. G., Ioannou, I., \& Serafeim, G. (2014). The impact of corporate sustainability on organizational processes and performance. Management Science, 60(11), 2381-2617. https://doi.org/10.1287/mnsc.2014.1984

Eccles, R. G., \& Serafeim, G. (2013). The performance frontier: innovating for a sustainable strategy. Harvard Business Review. https://hbr.org/2013/05/the-performance-frontierinnovating-for-a-sustainable-strategy

European Commission. (n.d.). Non-financial reporting. https://ec.europa.eu/info/business-economyeuro/company-reporting-and-auditing/companyreporting/non-financial-reporting_en

Fatemi, A., Glaum, M., \& Kaiser, S. (2018). ESG performance and firm value: the moderating role of the disclosure. Global Finance Journal, 38, 45-64. https://doi.org/10.1016/j.gfj.2017.03.001

Friede, G., Busch, T., \& Bassen, A. (2015). ESG and financial performance: aggregated evidence from more than 2000 empirical studies. Journal of Sustainable Finance and Investment, 5(4), 210233. https://doi.org/10.1080/20430795.2015.1118917

Giese, G., Lee, L.-E., Melas, D., Nagy, Z., \& Nishikawa, L. (2019). Foundations of ESG investing: How ESG affects equity valuation, risk, and performance? Journal of Portfolio Management, 45(5), 1-15.

https://doi.org/10.3905/jpm.2019.45.5.069 
Gurvitsh, N., \& Sidorova, I. (2012). Survey of sustainability reporting integrated into annual reports of Estonian companies for the years 20072010. Procedia Economics and Finance, 2, 26-34. https://doi.org/10.1016/S2212-5671(12)00061-5

Henisz, W. J., \& McGlinch, J. (2019). ESG, material credit events, and credit risk. Journal of Applied Corporate Finance, 31(2), 105-117. https://doi.org/10.1111/jacf.12352

Horváth, P., Pütter, J., Dagilienè, L., Dimante, D., Haldma, T., Kochalski, C., Král, B., Labaš, D., Lääts, K., Bedenik, N. O., Pakšiová, R., Petera, P., Ratajczak, P., Buhovac, A. R., Sava, A., Voiculon, S., Tirnitz, T. J., \& Wagner, J. (2017). Status quo and future development of sustainability reporting in Central and Eastern Europe. Journal of East European Management Studies, 22(2), 221243. https://doi.org/10.5771/0949-6181-2017-2-221

Kocmanova, A., Docekalova, M., Nemecek, P., \& Simberova, I. (2011). Sustainability: Environmental, social and corporate governance performance in Czech SMEs. In Proceedings of WMSCI 2011 - The 15th World Multi-Conference on Systemics, Cybernetics, and Informatics (pp. 94-99). https://www.academia.edu/31609741/Sustainabilit y_Environmental_Social_and_Corporate_Governa nce_Performance_in_Czech_SMEs

Kocmanova, A., Docekalova, M. P., \& Nemecek, P. (2016). Comparing the composite indicator index corporate sustainability and the predictive model an application on Czech manufacturing companies. In Proceedings of WMSCI 2016 - The 20th World Multi-Conference on Systemics, Cybernetics and Informatics (pp. 13-18).

https://pdfs.semanticscholar.org/dd65/c96424cd60 05673eee912556953866dfccc1.pdf

KPMG. (2017). The KPMG survey of corporate responsibility reporting 2017.

https://assets.kpmg/content/dam/kpmg/xx/pdf/ 2017/10/kpmg-survey-of-corporate-responsibilityreporting-2017.pdf

Mervelskemper, L., \& Streit, D. (2017). Enhancing market valuation of ESG performance: is integrated reporting keeping its promise? Business Strategy and the Environment, 26(4), 536-549.

https://doi.org/10.1002/bse.1935
NASDAQ. (2019). ESG Reporting Guide 2.0 - a support resource for companies. https://www.nasdaq.com/docs/2019/11/26/2019ESG-Reporting-Guide.pdf

Roca, L. C., \& Searcy, C. (2012). An analysis of indicators disclosed in corporate sustainability reports. Journal of Cleaner Production, 20(1), 103118. https://doi.org/10.1016/j.jclepro.2011.08.002

Rudžionienè, K., Pučètaitė, R., \& Vaičiulytė, I. (2016). Trends and determinants of social and environmental information disclosure in Lithuanian companies: a literature review. Zeszyty Teoretyczne Rachunkowości, 88, 143-162.

http://cejsh.icm.edu.pl/cejsh/element/bwmeta1.ele ment.desklight-1ad72d50-9dd4-436e-aa6ac8960f1a8391/c/11_B5_Rudzioniene.pdf

Tamimi, N., \& Sebastianelli, R. (2017). Transparency among S\&P 500 companies: an analysis of ESG disclosure scores. Management Decision, 55(8), 1660-1680. https://doi.org/10.1108/MD-01-2017-0018

van Duuren, E., Plantinga, A., \& Scholtens, B. (2016). ESG integration and the investment management process: fundamental investing reinvented. Journal of Business Ethics, 138, 525-533. https://doi.org/10.1007/s10551-015-2610-8

Velte, P. (2017). Does ESG performance have an impact on financial performance? Evidence from Germany. Journal of Global Responsibility, 8(2), 169-178. https://doi.org/10.1108/JGR-11-2016-0029

von Wallis, M., \& Klein, C. (2015). Ethical requirement and financial interest: a literature review on socially responsible investing. Business Research, 8(1), 6198.

https://doi.org/10.1007/s40685-014-0015-7

York, J. (2009). Why wine is not glue? The unresolved problem of negative screening in socially responsible investing. Journal of Business Ethics, 85(1), 83-95.

https://doi.org/10.1007/s10551-008-9949-z 